TARGHETTA (Fabio), La Capitale dell'impero di carta. Editori per la scuole a Torino nella prima metà del Novecento.

Torino : Società Editrice Internazionale, 2007, 274 p.

\title{
Mariella Colin
}

\section{OpenEdition}

\section{Journals}

Édition électronique

URL : https://journals.openedition.org/histoire-education/620

DOI : $10.4000 /$ histoire-education. 620

ISSN : 2102-5452

Éditeur

ENS Éditions

Édition imprimée

Date de publication : 1 janvier 2008

Pagination : 150-151

ISBN : 978-2-7342-1113-6

ISSN : 0221-6280

Référence électronique

Mariella Colin, «TARGHETTA (Fabio), La Capitale dell'impero di carta. Editori per la scuole a Torino nella prima metà del Novecento. », Histoire de l'éducation [En ligne], 117| 2008, mis en ligne le 20 octobre 2008, consulté le 20 mai 2021. URL : http://journals.openedition.org/histoire-education/620 ; DOI : https://doi.org/10.4000/histoire-education.620

Ce document a été généré automatiquement le 20 mai 2021.

(c) Tous droits réservés 


\section{TARGHETTA (Fabio), La Capitale dell'impero di carta. Editori per la scuole a Torino nella prima metà del Novecento.}

Torino : Società Editrice Internazionale, 2007, 274 p.

\section{Mariella Colin}

\section{RÉFÉRENCE}

\section{TARGHETTA (Fabio),}

La Capitale dell'impero di carta. Editori per la scuole a Torino

nella prima metà del Novecento.

Torino : Società Editrice Internazionale, 2007, 274 p.

1 Cet ouvrage ajoute une nouvelle pièce au vaste édifice que sont actuellement en train de construire les historiens de l'édition et de l'école, en explorant un domaine qui relève à la fois de l'industrie, de l'éducation et de la culture. Alors que le secteur du livre scolaire et du livre de jeunesse, traditionnellement occupé en Italie par des éditeurs mineurs, avait été longtemps négligé par les universitaires, son étude est devenue à l'heure actuelle l'objet d'un intérêt renouvelé. Tandis que la recherche collective aboutit à des résultats d'une taille monumentale (tel le remarquable TESEO - Tipografi e editori scolastico-educativi dell'ottocento ${ }^{1}$-, véritable somme sur tous les éditeurs et typographes de livres scolaires et éducatifs du XIX ${ }^{e}$ siècle), les monographies reconstruisent l'histoire des maisons d'édition spécialisées. Le volume de Fabio Targhetta est consacré aux éditeurs turinois qui, du début du $\mathrm{XX}^{\mathrm{e}}$ siècle jusqu'à la Seconde Guerre mondiale, connaissent un essor important et contribuent à faire de la grande ville piémontaise la «capitale d'un empire de papier » (telle est la 
signification du titre : la capitale dell'impero di carta), assis sur les manuels pour les écoles et la production pédagogique au sens large.

Dans cet «empire éditorial» transalpin, ce sont les éditeurs conservateurs et catholiques qui jouent un rôle moteur. Le premier est Paravia, qui, dès la fin du $\mathrm{XIX}^{\mathrm{e}}$ siècle, a tenu le premier rang dans le secteur du livre scolaire (avec le Florentin Bemporad). Après la Première Guerre mondiale, son nouveau directeur, Pietro Gorgolini, "fasciste de la première heure » et ami de Mussolini, aura à cœur non seulement de développer le marché de l'édition, mais aussi d'affirmer le caractère «national» de ses fournitures (des blouses d'écoliers aux cartes murales). Dans les années 1920, avant la proclamation de la dictature, la maison cherche à améliorer la qualité de ses manuels et livres de lecture, en rénovant sa production en conformité avec les directives des pédagogues néo-idéalistes. Dans les années 1930, en revanche, livres d'école et livres de loisir s'inscriront trop souvent dans la droite ligne de la « révolution en chemise noire ».

3 La deuxième maison d'édition "leader» est la SEI (Società Editrice Internazionale), directement issue de l'action de dom Giovanni Bosco en faveur de la Buona Stampa (la presse d'inspiration religieuse, vue comme l'expression d'une croisade catholique contre l'État libéral). De la typographie de l'Oratorio salésien, on passera à la Libreria Salesiana, puis à la Società Anonima Internazionale per la Diffusione della Buona Stampa, devenue en 1919 la Società Editrice Internazionale. Comme chez Paravia, c'est par l'action énergique de son directeur, Giuseppe Caccia, que la maison connaîtra une croissance considérable. Il remplacera le livre religieux par le livre scolaire et donnera à la SEI une image "laïque», plus conforme à la modernité du nouveau siècle. Sous le régime mussolinien, la SEI jouira de la protection de Cesare Maria De Vecchi (l'un des quadrumviri de la marche sur Rome) et profitera également de l'introduction de la religion parmi les enseignements obligatoires à la suite du Concordat de 1929.

L'ouvrage de Fabio Targhetta, clair et bien informé, permet de mieux connaitre la contribution des éditeurs scolaires à la construction d'un modèle éducatif qui, de fait, a constitué un facteur non négligeable de la formation de la conscience italienne, nationale d'abord, fasciste ensuite.

\section{NOTES}

1. Milano, Editrice Bibliografica, 2003, 760 p. 


\section{AUTEURS}

MARIELLA COLIN 